\title{
APPLICATION OF BABY WALKERS IN RUSSIA: EPIDEMIOLOGICAL ASPECTS
}

\author{
A.N. Sharov ${ }^{1}$, A.V. Krivova ${ }^{1}$, S.S. Rodionova ${ }^{2}$ \\ ${ }^{1}$ Tver State Medical University, 4 Sovetskaya Str., Tver, 170100, Russian Federation \\ ${ }^{2}$ N.N. Priorov's National Medical Research Center for Traumatology and Orthopedics, 10 Priorova Str., 127299, \\ Moscow, Russian Federation
}

As per various research data, from 42 to $90 \%$ families all over the world use baby walkers. There are some data implying that baby walkers prevent motor skills from their natural development and are to a certain extent dangerous for infants' health. Prevalence of damages associated with baby walkers varies from 7 to $50 \%$ according to different estimations. Our research goals were to determine reasons for application of baby walkers in Russia and their prevalence in Russian families; to assess levels and structure of children injuries caused by baby walkers and their influence on motor development and on walking pattern formation.

We performed three cohort pieces of research with pseudo-retrospective design. The overall sampling included 749 children; "baby-walker" groups consisted of 363 infants. We also performed an anamnestic questioning of parents with specially designed anonymous questionnaires. The research was accomplished on typical Russian territories (Rzhev and Rzhev district in Tver' region, population amounts to approximately 60.3 thousand people).

We detected that frequency with which baby walkers were applied among children on the examined territories was similar to average frequency detected worldwide and amounted to $62.11 \pm 18.5 \%$. Parents think that basic advantages and reasons for application of baby walkers are as follows: they make a child to develop faster; they keep a baby busy and help to keep it safe; they entertain a baby; it is a tradition. The detected level of injuries caused by baby walkers was relatively low $(15.4 \%)$. There were no injuries that require medical aid. Our research didn't reveal any statistically authentic influence exerted by baby walkers on formation of acquired static deformations in infancy. There is also no statistically authentic discrepancy between children from "baby walkers" group and "without baby walkers" group in the examined sampling when they reach the following stages in their development: "standing with a support" and "moving with a support". But on average, children who grew with baby walkers started to walk on their own with a 13-day delay. We detected a statistically authentic strong correlation $(p<0.01)$ between application of baby walkers and risk of tiptoe walking $(R R=3.56 ; C I 2.56-4.99$ for $95 \%$ provision). A longer period of tiptoe walking in "baby walkers" group confirms that baby walkers exert long-term negative influence on walking pattern structure. We detected the following additional (attributable) population risk (PAR): absence of walking on one's own, PAR=4.45-5.3\%; tiptoe walking, PAR=19.6-23.4\%. Application of baby walkers in families from the examined population decreased from 52.03 to $43.66 \%$ and it means that active informative campaigns aimed at explaining baby walkers dangers to parents and guardians were quite efficient. It is advisable to perform further research on the matter.

Key words: baby walkers, children injuries, stages in motor development, delay in onset of walking, tiptoe walking, idiopathic toe-walking.

Any parents want their baby to develop as fast and actively as possible and they are ready to do anything to help in the process. It's an integral part of our biological program, an instinct that makes us take care of our offspring. Baby walkers were initially invented as a toll for providing this help;

but they turned out to be a rather controversial device. As per data obtained in various research
[1-8], including domestic one $[9,10]$, baby walkers prevent motor skills from their natural development and even cause a certain threat for health, primarily related to additional traumatism.

Examinations of baby walkers ${ }^{1}$ as a phenomenon that influences health have been accomplished in various research all over the world since late 80ties last century. These

(C) Sharov A.N., Krivova A.V., Rodionova S.S., 2018

Alexander N. Sharov - a post-graduate student at Department for Traumatology and Orthopedics (e-mail: sklif79@yandex.ru, tel.: +7 (905) 600-33-09).

Alla V. Krivova - Associate Professor, Doctor of Medical Sciences, Associate Professor at Department for Traumatology and Orthopedics (e-mail: info@tvgma.ru; tel.: +7 (4822) 32-17-79).

Svetlana S. Rodionova - Doctor of Medical Sciences, Professor, head of Scientific and Clinical Center for Osteoporosis Treatment (e-mail: cito@ cito-priorov.ru; tel.: +7 (499) 940-97-47).

${ }^{1}$ Baby walkers is a technical device. It has a base made of hard plastic sitting on top of wheels with additional appliances that help to keep a baby in a vertical position. 
examinations can be divided into three basic groups epidemiological ones, examinations of injuries associated with baby walkers, and assessment of their effects on motor skills development.

Epidemiological aspects related to application of baby walkers have been examined since early 90ties last century. The first examination on the issue was performed in Denia (Spain) in 1992-1993. S.L. Santos et al. conducted a questioning that lasted from November 1, 1992 to January 31, 1993 and included parents of 207 children aged from 3 to 24 months [11]

The authors revealed that $42 \%$ children aged from 4.3 to 13.4 months were at least once put into baby walkers, and parents of $46.7 \%$ out of this number applied them every day. They also revealed a statistically significant inverse correlation $(r>-0,6)$ between frequency and duration with which baby walkers were applied and a mother's education. It was shown that parents reported on the following presumable advantages of baby walkers: $34.2 \%$ stated it was comfortable for parents; $10.9 \%$ said baby walkers entertained their babies; $12.9 \%$ believed baby walkers helped their children to develop[; $46.3 \%$ respondents didn't mention any advantages.

Also parents stated there were some hazards caused by application of baby walkers; thus, 33.5\% mentioned deformation of lower extremities; $43.0 \%$, accidents, including $33.5 \%$ mentioning injuries, and $12 \%$, falling off the stairs; $27.2 \%$ said there were no any hazards. As per data collected by the authors, $24.9 \%$ children who spent some time in baby walkers were injured $(76.2 \%$ fell; $14.3 \%$ had ambulatory injuries, and $4.8 \%$ were taken to hospitals to be treated after an injury). Injuries much more frequently occurred among boys.

The next research was performed in Baltimore in 1993 by Doctor A. Trinkoff and Doctor P.L. Parks [12]. They questioned parents who had children aged 312 months and revealed that baby walkers were used quite frequently, in $66 \%$ cases $(n=77)$. It is remarkable that this frequency was even higher among low-educated parents. Parents mentioned the following reasons for application of baby walkers: to entertain a baby, to limit its movements, to help it to develop locomotor skills.
Data were collected via individual questioning performed among parents; the total number of participants were 158 people, and 55\% respondents stated they applied baby walkers. The basic reasons for that were the following: baby walkers brought positive emotions to babies; application of such devices started with the eldest child in a family (a tradition). No respondents in a "baby walkers" group thought that safety issues could make them abandon baby walkers; $48 \%$ respondents in a "without baby walkers" group stated that thinking about safety would persuade them to stop using the device. $12.5 \%$ children who spent some time in baby walkers had at least one injury during this period.

In 1998 American scientists conducted standard interviews among 254 people (parents or guardians) who applied for medical aid to a clinic within a month in which the research took place [14]. Parents of $77 \%$ (n-119) firstborns and $85 \%$ of the second and consequent child applied baby walkers. The researchers didn't reveal any statistically authentic discrepancies between children from "baby walkers" and "without baby walkers" groups as regards a child's sex, being the eldest or not in a family, parents' race or education, or a type of guardianship. There were also no discrepancies between the groups related to information given by a pediatrician as regards hazards caused by baby walkers application. 97\% parents in a "baby walkers" group heard about such devices prior to a childbirth but $65 \%$ didn't start using them after a child was born. $61 \%$ of those who applied the device stated there was no external influence that made them buy it; $75 \%$ bought the device on their own. These decisions didn't correlate with parents' education or seniority of a child in a family. Finally, $78 \%$ parents thought baby walkers were useful, and $72 \%$ parents stated the device fastened the development of an independent walking skill ${ }^{2}$.

The research conducted by two British scientists D. Kendrick and P. Marsh in 1998 contains data obtained via questioning of parents with children aged 3-12 months; the parents were registered in each of 36 ambulances for primary reception in Nottingham, Great Britain $(n=2,152)$ [15]. The number of answers amounted to $74 \%$. $50 \%$ families applied baby walkers.

\footnotetext{
${ }^{2}$ Independent walking is walking on two feet on one's own, without any support, making more than 5 steps, with further progress.
} 
It was detected that application of baby walkers wasn't authentically correlated with either living on hardship allowance $(O R=1,42 ; 95 \%$ $C I=1,02-1,99)$, or renting a housing $(O R=1,46$; $95 \% C I=1,04-2,04)$, dwelling in a poor district $(O R=1,42 ; 95 \% C I=1,06-1,91)$, parents being unemployed $(O R=0,64 ; 95 \% \quad C I=0,41-0,99)$. Families that applied baby walkers installed smaller number of gates that lock the staircases $\left(\chi^{2}\right.$ $=4,36,1 D F, p=0,037)$ and fire control systems $\left(\chi^{2}=6,80,1 D F, p=0,009\right)$. in their houses. There were a lot of probable home hazards in their houses (Mann-Whitney test $U, Z=-2,90$, $p=0,004)$. However, there were no differences detected between risks of injuries and risks related to home hazards when such risks were assessed for a group of parents who bought and applied baby walkers.

In 1999 D. DiLillo, A. Damashek, and L. Peterson performed a retrospect phone questioning that comprised 329 mothers; they gave information on application of baby walkers and stationary playpens for their 463 children born in Columbia, Missouri, from January 1994 to April 1999 [16]. It was revealed that a share of families who applied baby walkers dropped steadily from 1994 to 1999 while application of playpens grew over the same period. 48.9\% out of 329 questioned mothers stated they put at least one baby in their family into baby walkers. Frequency of application was distributed as follows: $14.1 \%$ applied the device only once or twice; $16.5 \%$, "from time to time"; $15.5 \%$, "several times a month"; $5.3 \%$, every week; $48.5 \%$, every day. Overall, $88 \%$ mothers were aware of risks related to injuries and it was the most frequent reason for abandoning baby walkers. But still, 38\% of respondents applied the device.

Parents mentioned various reasons that made them buy baby walkers, including "to entertain a baby", "to make it develop faster", the device was easy to buy and quite affordable; some parents mentioned also that stationary playpens were safer.

In 2003 in Singapore N.C.Tan and his colleagues selected parents of 445 children who were brought to clinics when they were 4-6 months old for scheduled immunization [17] These parents were questioned, and standardized questionnaires were applied in the process. The research revealed that $71.2 \%$ (311 out of 437 parents) applied baby walkers when their child was 9 months old. $66.7 \%$ parents didn't know about injuries related to baby walkers and only $37.5 \%$ were aware of some alternative devices. Besides, $48.3 \%$ respondents believed baby walkers helped their children to develop, although even at that time (2003, author's note) there were assumptions that the device actually postponed independent walking. In addition, it was detected that $20.1 \%$ parents took safety precautions when applying such devices. The researchers determined factors that statistically authentically increased application of baby walkers in families. They were parents' education; overall incomes of a family; housing; availability of baby walkers; an opinion that baby walkers made for early independent walking. Such factors as awareness of hazards, alternative devices, and total number of children in a family, didn't have any statistically authentic influence on decisions made by parents on the issue.

The research also revealed 24 "baby walkersrelated" injuries and it accounted for $7 \%$ out of all the respondents $(n=311)$. Prevailing injuries were falls on plane surface $(5.5 \%)$, and falling off the stairs $(14.9 \%)$.

In 2007-2008 in Iran Doctors F. Shiva, F. Ghotbi, and S.F. Yavari examined families who visited medical clinics in Teheran with their children aged from 6 months to 2 years [18]. They applied a standard questionnaire to conduct questioning among parents. The results were assessed via comparing between two groups, "baby walkers" one and "without baby walkers" one. 414 (54.5\%) children (216 girls and 198 boys) spent some time in baby walkers. Baby walkers were much more frequently applied in families with just one child ( $p$-value is 0.009) and in families where parents were better educated ( $\mathrm{p}$-value $<0.001$ ).

$76.8 \%$ parents of children from "baby walkers" group thought the device promoted early walking (against $8.2 \%$ parents of children from "without baby walkers" group). $44.7 \%$ parents who applied baby walkers and $22.3 \%$ who didn't do it knew about hazards related to the device. 136 parents $(60.17 \%)$ stated they applied baby walkers "to teach a child to walk earlier"; 57 (25.2\%) wanted "to entertain a baby"; 23 (10.17\%) said "it was a tradition"; $10(4.4 \%)$ stated it was "just their wish" or there was "no reason at all".

The research didn't reveal any serious injuries among babies put into baby walkers, but still $14.1 \%$ babies had insignificant injuries of soft tissues while being in baby walkers.

As per data obtained by D.G. Dogan et al. [19] parents of 495 children aged from 2 months to 5 years who visited consultative clinics for child care at Fatih University Hospital in Ankara (Turkey) applied baby walkers in $75.4 \%$ cases. Female sex (OR 1.82, 95\% CI 1.19-2.78) and 
lower education of a mother (OR $0.37,95 \%$ CI 1.18-0.74) were parameters that statistically authentically increased application of such devices. Injuries were rare (7.8\%). Only $18.6 \% \quad(\mathrm{n}=92)$ families received relevant consultations from their pediatricians.

In 2015 in the UAE Doctor M. Grivna et al. [20] questioned 696 female 12th grade students who attended four state schools, $55 \%(n=385)$ out of them being the UAE citizens. Girls from three "scientific" classes and three "art" classes gave their answers to questions and stated that $90 \%(\mathrm{n}=$ 619) families used to apply or still applied baby walkers. As for reasons for application of the device, $92 \%$ respondents mentioned safety of baby walkers, $11 \%$ thinking the device was completely safe, and $74 \%$, that it was moderately safe. Only $16 \%$ noted that application of baby walkers could cause injuries.

Overall, a share of children who grew in families where baby walkers were applied varies from $42 \%$ to $90 \%$ in various populations (Figure
1), average value being $62.11 \% \pm 18.5=$ 43.61;80.61(CI=99\%).

Parents mention the following basic advantages and reasons for application of baby walkers: faster development of a baby (8 out of 10 examinations); babies being occupied with something and being safe (8 out of 10 examinations); entertainment for babies ( 3 out of 10 examinations); traditions or absence of reasons (3 out of 9 examinations).

Data on additional factors that influence baby walkers application in samplings are rather controversial: parents' education was detected to exert statistically authentic influence in 4 examinations $[4,8,11,12]$, but the correlation was inverse in 3 of them $[4,8,12]$, and direct in the remaining one [11], and there was an unreliable correlation detected in one more examination [6]. Income level was detected to be significant in one examination [8], and insignificant in another [14]. Therefore, it is difficult to authentically spot out an additional risk group in relation to the examined problem.

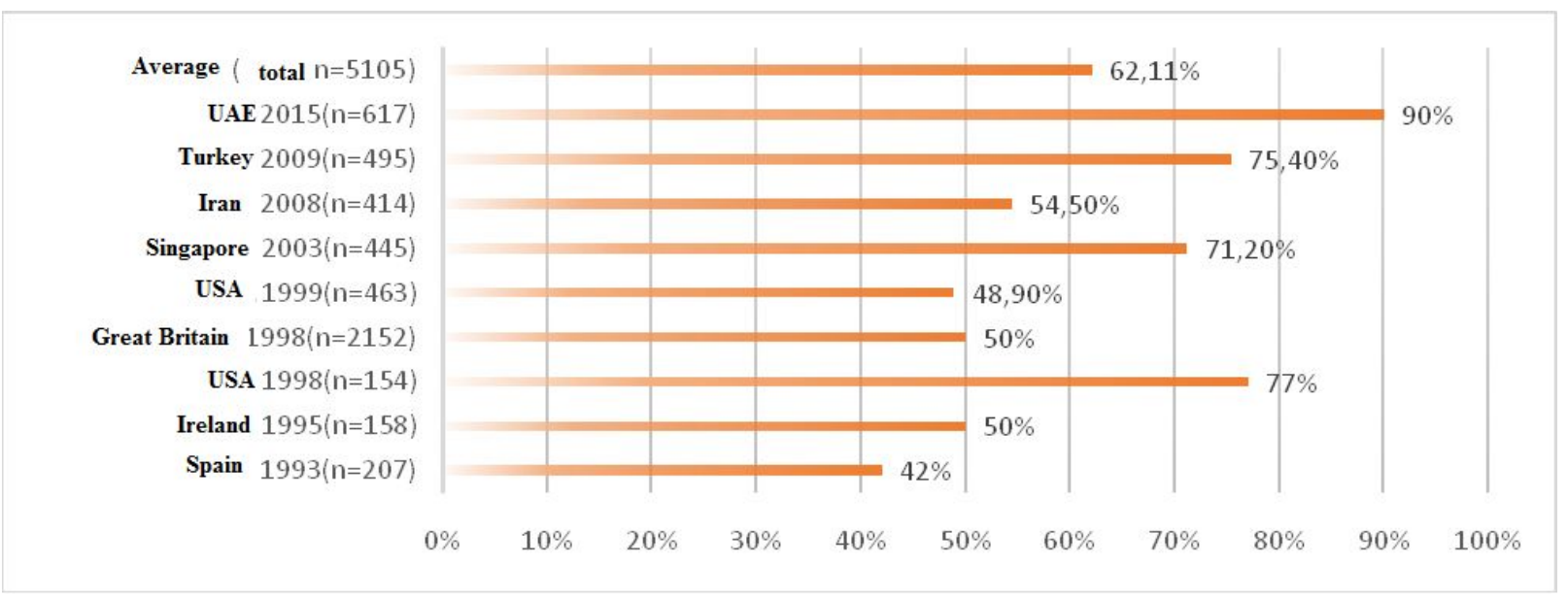

Figure 1. A share of children who were put in baby walkers in various samplings. As per data taken from foreign research [11, 13-20].

Various injuries, as well as gravity of traumas, up to deaths [21] are naturally considered by world scientists to be the basic problem related to baby walkers. As per results obtained in the examinations described above, as well as some other research, prevalence of injuries related to baby walkers various from $7 \%$ (Singapore, 2003) [17] to $50 \%$ (Italy, 1981) [22]; as per the biggest sampling, n-57500 (the USA 1987), injuries accounted for $35 \%$ [23]. The structure of traumatism is most profoundly described in a work that occupies the core place in studies on "baby walkers" traumatism; the work was published by scientists from Ohio (the USA) who analyzed 197,200 (sic!) injuries related to baby walkers that occurred over a period from 1990 to 2001. The following distribution of injuries as per various groups was detected among infants younger than 15 months [24]: surface soft tissue traumas (53,0\%); closed craniocerebral injuries (25.1\%); lacerations and bruises $(10.1 \%)$; damages to bones and joints, fractures/dislocations (5.2\%); burns $(2.2 \%)$; other injuries $(4.4 \%)$. 
As per data taken from some research, falling off the stairs causes the gravest "baby walkers"related injuries [24-27]. Such falls are authentically related to skull fracture risks: $\mathrm{RR}=3.28$ (95\% CI 1.35-7.98) [27] and OR 3.74 ( $<<0,01 ; 95 \%$ CI 3.42-4.09) [24]. Injuries that are not caused by falling off the stairs are predominantly ambulatory, or they don't even require any medical aid [24-31].

There has been a lot of research performed in various countries in different years on assessing influence exerted by baby walkers on motor skills $[1-3,5,6,8]$, and the results are rather controversial. For example, reviews by M.C. Mancini et al. contain the following conclusion: "from a critical point of view, we can't make any precise judgment on actual effects produced by baby walkers when motor skills develop typically due to insufficient evidence base" [32]. Patricia Burrows and Peter Griffiths (2002) came to a conclusions that "results of two examinations considered in the review didn't reveal any significant influence exerted by baby walkers on a start of independent walking. Cohort research revealed that application of baby walkers delayed it, as generalized analysis of four cohort examinations revealed delays within an interval from 11 to 26 days" [33].

Tiptoe walking ${ }^{3}$ occurs from the very beginning of independent walking, as per data by foreign authors [34-39]. This walking pattern is thought to be a pathologic one at 2-3 years, but prior to this age it is considered to be a part of a normal walking formation [40]. As regards influence exerted by baby walkers on motor skills, there is an assumption that the device can possibly change locomotor pattern and lead to tiptoe walking (Martín-Casas P et al.) [41]). Our empirical observations also allow us to make similar assumptions.

Data and methods. Data for the work were obtained via three cohort examinations which were pseudo-retrospective; the examinations were performed in a children clinic at Rzhevskaya Central District Hospital, and four pre-school children facilities in Rzhev, Tver' region. The overall number of children in sampling was equal to $749 ; 363$ children were in "baby walkers" group.

The first examination (No. 1) entitled "Epidemiologic aspects related to application of baby walkers and correlation with talipes valgus" was performed in February - September 2016 among children born from January - September
2015 In Rzhev, Tver' region. We excluded patients whose parents couldn't give exact necessary data, as well as patients with grave congenital pathologies (16 children totally). The sampling included 268 babies aged 11-18 months. We performed our research via anamnestic questioning among parents with a standardized, specially designed, and anonymous questionnaire; we also conducted an objective assessment of heel bone angle. The results were then collected in Table 1

Table 1

Examination results registration

\begin{tabular}{|l|l|l|l|l|}
\hline No. & 1 & 2 & $\ldots$ & 10 \\
\hline Period of application & & & & \\
\hline Daily application & & & & \\
\hline Age & & & & \\
\hline Sex & & & & \\
\hline Reasons for application & & & & \\
\hline Talipes valgus, other pathologies & & & & \\
\hline
\end{tabular}

We initially grouped the data regarding application of baby walkers; additional grouping was made as per sex, reasons for application of such devices, "baby-walkers"-related injuries, and talipes valgus. We calculated and analyzed relative values (extensive parameters) for separate groups and then designed a fourfold table to assess influence exerted by application of baby walkers on occurrence of acquired statistical talipes valgus. We also calculated Chi-square criterion.

The second examination (No. 2) entitled "Influence exerted by baby walkers on motor skills development in infants" was conducted from September 2014 to September 2015. The sampling included all infants who were healthy at the moment of prophylaxis inspection by a traumatologist-orthopedist; all of them were born in period from September 2013 to September 2014 in Rzhev, Tver' region. We excluded patients with delays in motor development caused by diseases in the locomotor or nervous system, with congenital or acquired hypotrophy, as well as children whose parents couldn't provide us with all necessary data. Children weren't divided as per sex. The sampling included 11-15 month old infants. Totally 514 children were born in the period, and we questioned parents of 408 children (79.3\%), and only $358(69.6 \%)$ babies were included into research sampling. We performed our research via anamnestic questioning among parents with a standardized, specially designed, and anonymous

\footnotetext{
${ }^{3}$ Tiptoe walking is a manner in which a baby moves on two feet without stepping on its heels, making more than 5 consequent steps, and repeats it for at least a week when starting to walk independently. Periods when a baby was lifted on tiptoes without moving were not taken into account.
} 
questionnaire. The data were then collected in Table 2 by a medical expert (Table 2).

Table 2

Examination results registration

\begin{tabular}{|l|l|l|l|l|}
\hline \multicolumn{1}{|c|}{ Parameter } & 1 & 2 & $\ldots$ & 10 \\
\hline Age (months) & & & & \\
\hline Diagnosis at 1-3- months. & & & & \\
\hline $\begin{array}{l}\text { Standing with support } \\
\text {...(months) }\end{array}$ & & & & \\
\hline $\begin{array}{l}\text { Walking with support } \\
\text { from...(months) }\end{array}$ & & & & \\
\hline $\begin{array}{l}\text { Independent walking } \\
\text { from...(months) }\end{array}$ & & & & \\
\hline Tiptoe walking (yes/no) & & & & \\
\hline $\begin{array}{l}\text { Application of baby walkers } \\
\text { (yes/no) }\end{array}$ & & & & \\
\hline $\begin{array}{l}\text { Minutes per day (in baby walkers) } \\
\text { Total number of days (in baby } \\
\text { walkers) }\end{array}$ & & & & \\
\hline
\end{tabular}

We performed an interval (as per babywalkers/day index $)^{5}$ grouping of children who walked on tiptoes.

We initially grouped our sampling taking into account a stage and a factor for application of baby walkers as well as period of their application (Figure 2).

Data obtained for specific groups were statistically processed and extensive values were calculated for each group. We designed weighted leveled-off series for development stages. Levelingoff was accomplished via upsizing an interval. We determined series variations and analyzed average values. Mean weighted value of the general sampling was calculated as per Student's technique (taking into account t-distribution of the samplings) for $99 \%$ confidence intervals. Obtained general average stages were compared with data taken from the WHO Motor Development Study [42], via calculating pair Student's t-test ( $\mathrm{p}$-value $\leq 0.01$ and $\leq 0.05$ ).

A discrete series for baby-walkers/day index was divided into intervals and variation series were drawn up for bay-walkers/day intervals $<1 \mathrm{bw} / \mathrm{d}$ and $\geq 1 \mathrm{bw} / \mathrm{d}$; mean values were calculated and compared with previously obtained data. These intervals were selected as the most representative ones for assessing discrepancies.

At the next stage we assessed significance of discrepancies in mean group values for different ages that corresponded to various stages in a child's development. To detect the most representative statistical technique, we calculated normalcy of distribution; asymmetry of distribution; Fischer's test $(\mathrm{F})$ for assessing equality of general dispersions; and two-sample Kolmogorov-Smirnov test for assessing identity of distribution laws in pair groups. bearing all these calculations in mind, we chose Student's pair t-test and Mann-Whitney U-test. We calculated significance of discrepancies between mean group values (including those for specific bw/s intervals); discrepancies at $\mathrm{p}$-value $\leq 0.01$ and $\leq 0.05$ were considered to be authentic. In addition, we drew up a box diagram and a summary table containing general mean values for all groups and stages allowing for $99 \%$ confidence interval.

At the next stage we tried to reveal a correlation between a period of time spent in babywalkers a day (both for the whole series of values and for specific intervals) and age of various stages in development of locomotion. We applied correlation analysis to calculate the following coefficients: parametric Pierson's test and nonparametric $\rho$-Spearman test, $\tau(\mathrm{c})$-Kendall test, and $\tau(\mathrm{b})-$ Kendall test. A statistic hypothesis was considered to be authentic at $p<0,05$. Within specific elements of one-factor regression analysis we built scattering diagrams, a regression straight as per the least square method with $95 \%$ confidence intervals, and calculated coefficients of determination (R2) for similar stages and intervals.

Then we examined a group of children who didn't walk on their own at the moment of our examination (n-61). Primarily we accomplished an

\footnotetext{
${ }^{4}$ Standing with support is a vertical position of a baby when it stands on two feet for more than 5 minutes on its own but supporting itself with some objects or an adult's hand.

${ }^{5}$ Baby walkers/day index $(b w / d)$ is equal to a 1 hour spent by a baby in baby walkers a day during 1 month. Example: 30 minutes per day during 1 months is 0.5 bw/d; 2 hours per day during 3 months is 6 bw/d; 6 hours per day during 5 months is 30 bw/d.
} 


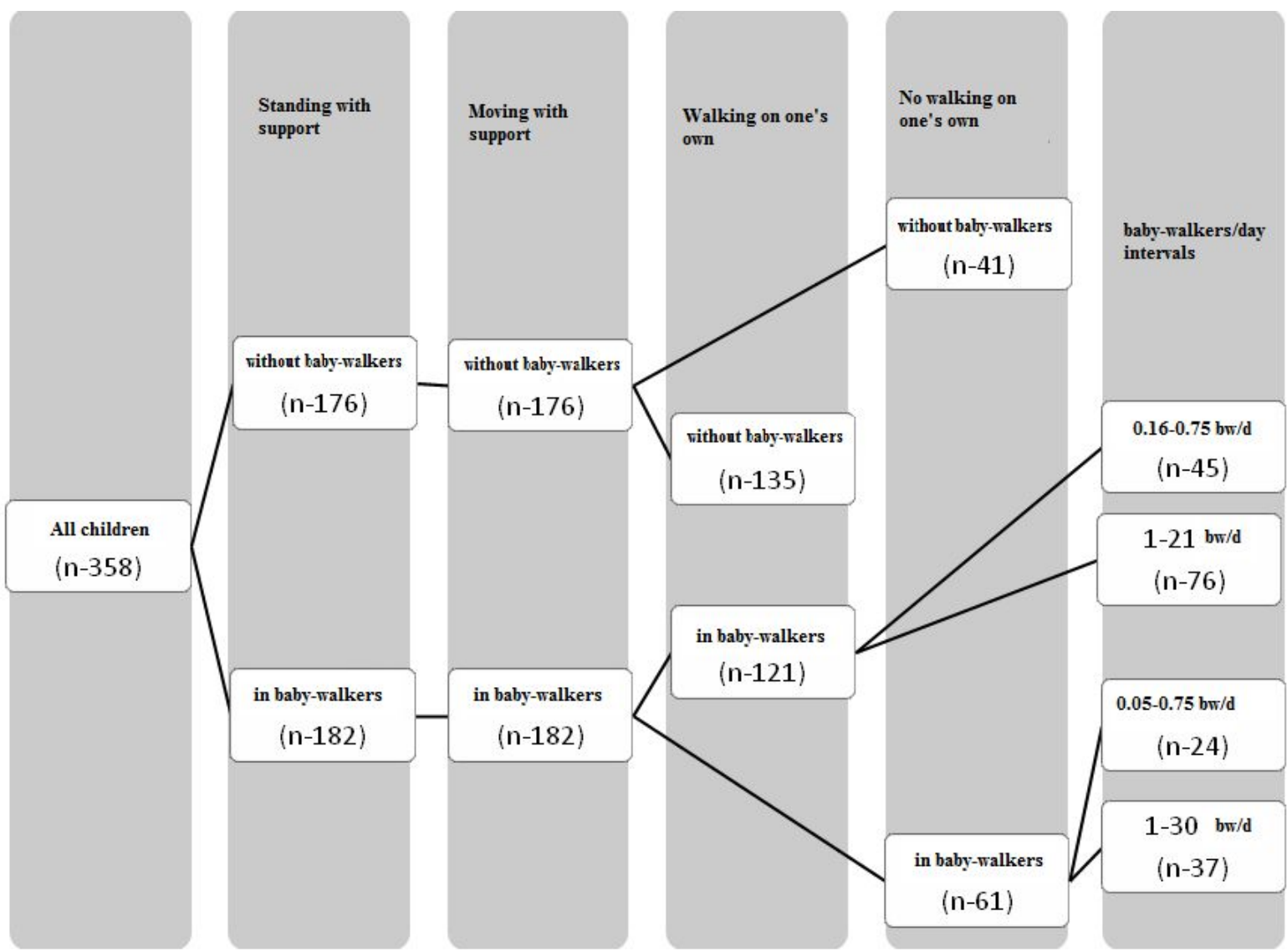

Figure 2. Research sampling grouping - influence exerted by baby walkers on motor skills development in children

interval grouping as regards bw/day index, and $<1$ bw/d and $\geq 1 \mathrm{bw} / \mathrm{d}$ intervals were selected as the most representative for assessing discrepancies. To assess this group, we applied correlation and regression analysis to reveal influence exerted by baby-walkers on this phenomenon similar to the previous stage in calculations. We calculated $r-$ Pearson test, $\rho$-Spearman test, $\tau(\mathrm{c})$-Kendall test, and $\tau(b)-K e n d a l l$ test. A statistical hypothesis was considered to be authentic at $\mathrm{p}<0.05$. Then we drew up scattering diagrams and regression straights as per least square method and calculated coefficients of determination (R2).

To assess influence exerted by baby-walkers as a factor that prevents a baby from walking and a factor that makes a baby walk on tiptoes, we analyzed fourfold tables, determined Chi-square criterion and Pearson's contingency coefficient. A statistical hypothesis was considered to be authentic at $\mathrm{p}<0.05$. We also calculated relative risk (RR) and population attributive risk (PAR) with $95 \%$ confidence interval.

In addition, we accomplished interval (as per baby-walkers/day index) grouping of children who walked on tiptoes and calculated chi-square and
Pearson's test for each interval. A statistical hypothesis was considered to be authentic at $\mathrm{p}<0.01$. We again calculated relative risk (RR) and population attributive risk (PAR) at $\mathrm{CI}=95 \%$.

Our third examination (No.3) was entitled "Baby walkers and tiptoe walking". Data were collected from April 2016 to July 2016 in four preschool children facilities in Rhzev, Tver' region. We performed our research with an anamnestic questioning among parents with a standardized, specially designed and anonymous questionnaire. The results were then filled in the table by medical experts (Table 3 ).

We questioned 180 parents. If parents couldn't provide all the necessary data, their children were excluded from the examination. Precise data were given by 123 respondents; 64 infants $(52.03 \%)$ were put into baby-walkers at least once; $59(47.97 \%)$ were never put into the device. Our sampling had the following structure in terms of sex: 69 girls (54.31\%) and 54 boys (45.69\%). As for age, children were 18-41 months old. 
Table 3

\begin{tabular}{|c|c|c|c|}
\hline \multirow{2}{*}{\multicolumn{4}{|c|}{\begin{tabular}{|c|} 
No \\
\end{tabular}}} \\
\hline & & & \\
\hline Date of birth and sex of a child & & & \\
\hline $\begin{array}{l}\text { A diagnosis by a surgeon (orthope- } \\
\text { dist), if any }\end{array}$ & & & \\
\hline Tiptoe walking (yes/no) & & & \\
\hline If yes, than till what age & & & \\
\hline Applied baby-walkers (yes/no) & & & \\
\hline $\begin{array}{l}\text { Additionally: } \\
\text { Any anomalies related to walking } \\
\text { and lower extremities mentioned by } \\
\text { parents (for example, club-foot, } \\
\text { "crossed legs" etc.) (if any) }\end{array}$ & & & \\
\hline
\end{tabular}

First, we divided our sampling into groups as per baby-walkers application and tiptoe walking. Then we calculated and analyzed relative values (extensive parameters) for groups in the sampling. We drew up a fourfold table to assess influence exerted by baby-walkers as a factor promoting a specific walking pattern, tiptoe walking. We analyzed this fourfold table and calculated Chisquare, $\varphi$ criterion, Cramer's V test, Chuprov's coefficient, Pearson's contingency coefficient (C) (for p-value $<0.05$ ). Then we calculated risks of a child walking on its own but no toes with $95 \%$ confidence interval.

At the next stage, we calculated average values for an age at which babies stopped walking on tiptoes in "baby-walkers" group and "without baby-walkers" group with 95\% CI and assessed how appropriate it was to further apply Student's pair t-test; to do it, we calculated normalcy and asymmetry of distribution; Fischer's test (F) (at $\mathrm{p}=0.01$ ); two-sample Kolmogorov-Smirnov test. To estimate discrepancies between various ages at which babies from "baby-walkers" group and "without baby-walkers" group stopped tiptoe walking, we calculated Student's pair t-test $(\mathrm{p}<0.05)$ and Mann - Whitney U-test $(\mathrm{p}<0.01)$.

Then we again calculated additional population risk caused by baby-walkers as a pathological factor that promoted a higher tonus in extensor muscles of lower extremities taking into account all the results obtained in the 2nd and 3rd examination.

And finally, we assessed application of babywalkers in samplings involved in all three examinations.

We performed all the calculations in all three examinations with the following software: Microsoft Excel $^{\circledR}$, IBM $^{\circledR}$ SPSS $^{\circledR}$ Statistics and online calculators at http://app.statca.com, http://medstatistic.ru and http://www.semestr.ru on a compatible IBM with installed Microsoft Windows $10^{\circledR}$.

Two systematic errors were detected in all three examinations. The first one is a population bias as samplings include children belonging to Caucasian race but their exact ethnic structure is not defined (provisionally it was taken as similar to that of the Central Federal District in Russia). The second one is a recall bias and it is closely related to a structure of examinations, or, to be more exact, anamnestic questionings being their basic tool.

All parents or guardians gave their written informative consent to take part in the examinations.

Results of our own examinations. We started to assess our results with determining a volume and a structure of the phenomenon. The $1 \mathrm{st}$ examination chronologically was the last one; here we revealed the following distribution of babywalkers application by parents in Rzhev: the overall sampling included 268 children; "babywalkers" group was made up of 117 children (43.6\%), "without baby-walkers" group was made up of 151 children (56.4\%). As regards sex, the groups had the following structure: 70 girls (46.4\%) and 81 boys $(53.6 \%)$ in "without babywalkers" group, totally 151; 63 girls $(53.9 \%)$ and 54 boys $(46.1 \%)$ in "baby-walkers" group, totally 117. A distribution peculiarity was a bit higher number of girls in "baby-walkers" group.

Parents in Rzhev mentioned similar reasons that made them apply baby-walkers as their foreign counterparts. A priority motive was parents' desire to teach their baby to walk (40.17\%) and/or entertain it thus finding some free time for their own $(57.26 \%)$. Family traditions as a reason were mentioned by a very small number of respondents (2.56\%). However, while making a baby develop faster was chosen as a primary reason for application of baby-walkers as per data obtained in foreign research, more than a half parents in Russia $(57.26 \%)$ apply baby-walkers not to teach (help) a child to walk, but see it as a safe mean to limit a baby's freedom of movement; when a baby is in baby-walkers, parents can "stop looking after it and do something else".

We detected relative low number of damages among baby-walkers users in Russia (15.35\%). Falling on a plane surface or overturning was a prevailing cause of injuries, 17 out of 18 cases, and one child fell down due to hooking over a threshold. We didn't detect any falling off the stairs. All injuries were solely superficial, to be 
more exact, they were surface soft tissue traumas (bruises, sprains, and graze wounds). There were no applications for medical aid. Three respondents recalled having two or three injuries. In our opinion, children had such mild traumas due to their families living in one-floor flats and houses without any stairs inside. And injuries made parents abandon baby-walkers only in 5 cases.

Our attempt to reveal any possible early pathological outcomes of baby-walkers, such as acquired static deformations in infant age, was not successful in this research. We didn't detect any statistically authentic correlation between babywalkers and talipes valgus (Chi-square 3.743, $\mathrm{p}>0.05)$.

In our 2nd examination, we didn't detect any statistically authentic discrepancies in age at which various development stages began in comparison with data obtained in WHO Motor Development Study [42] (Table 4).

Table 4

Average weighted age at which development stages began in "without baby-walkers" groups in comparison with average world ones

\begin{tabular}{|c|c|}
\hline Stage & $\begin{array}{c}\text { Weighted mean (M) of the general sam- } \\
\text { pling }\end{array}$ \\
\hline \multirow{2}{*}{$\begin{array}{l}\text { Standing } \\
\text { with support }\end{array}$} & $\begin{array}{l}\text { 7.33 } \pm 0.17 ; \text { 7.16-7.5months }(99 \% \text { CI }) \\
\text { Rzhev }\end{array}$ \\
\hline & $\begin{array}{l}7.6 \pm 1.4 ; 6.2-9.0 \text { months }(95 \% \mathrm{CI}) \\
\text { worldwide }\end{array}$ \\
\hline \multirow{2}{*}{$\begin{array}{l}\text { Moving with } \\
\text { support } 6\end{array}$} & $\begin{array}{l}\text { 8.99 } \pm 0.16 ; 8.83-9.15 \text { months }(99 \% \text { CI }) \text {, } \\
\text { Rzhev }\end{array}$ \\
\hline & $\begin{array}{l}9.2 \pm 1.5 ; 7.7-10.7 \text { months }(95 \% \text { CI }) \\
\text { worldwide }\end{array}$ \\
\hline \multirow{2}{*}{$\begin{array}{l}\text { Walking on } \\
\text { one's own }\end{array}$} & $\begin{array}{l}\text { 10.57 } \pm 0.26 ; 10.31-10.83 \text { months }(99 \% \\
\text { CI), }{ }^{*} \text { Rzhev }\end{array}$ \\
\hline & $\begin{array}{l}12.1 \pm 1.8 ; 10.3-13.8 \text { months }(95 \% \mathrm{CI}) * \\
\text { worldwide }\end{array}$ \\
\hline
\end{tabular}

Note: *-confidence interval of the data obtained in WHO Motor Development Study overlaps values obtained in our research; it is confirmed by comparing average values with Student's pair t-test $t=1.65(p>0.05)$, therefore, discrepancies are not statistically significant. The detected discrepancy is a systematic error of selection (selection bias).

Similarly, there is no statistically authentic age discrepancy between "baby-walkers" and "without baby-walkers" groups as regards their age at which they start sanding with support and moving with support (Table 5).
We detected a delay in walking on one's own among "baby-walkers" children and it is well in line with data obtained in foreign research $[4,5]$, especially the work by Doctors Garrett M. et al. which was very close to ours as per its design and sampling structure (Northern Ireland, 2002) [6].

Table 5

Assessment of development stages age:

standing with support and moving with support in "baby-walkers" and "without babywalkers" group

\begin{tabular}{|l|c|l|}
\hline \multicolumn{1}{|c|}{ Stage } & Test & $\begin{array}{l}\text { Discrepancies }(\mathrm{p}- \\
\text { value })\end{array}$ \\
\hline \multirow{3}{*}{$\begin{array}{l}\text { Standing with } \\
\text { support }\end{array}$} & Student's $\mathrm{t}=0.67$ & $\begin{array}{l}\text { No discrepancies } \\
(\mathrm{p} \leq 0.01)\end{array}$ \\
\cline { 2 - 3 } & $\begin{array}{c}\text { Mann-Whitney } \\
\mathrm{U}=15425\end{array}$ & $\begin{array}{l}\text { No discrepancies } \\
(\mathrm{p}=0.5316)\end{array}$ \\
\hline \multirow{2}{*}{$\begin{array}{l}\text { Moving with } \\
\text { support }\end{array}$} & $\begin{array}{c}\text { Student's } \mathrm{t}=0.63 \\
\text { No discrepancies } \\
(\mathrm{p} \leq 0.01)\end{array}$ \\
\cline { 2 - 3 } & $\begin{array}{c}\text { Mann-Whitney } \\
\mathrm{U}=16868\end{array}$ & $\begin{array}{l}\text { No discrepancies } \\
(\mathrm{p}=0.4797)\end{array}$ \\
\hline
\end{tabular}

Overall delay in walking on one's own for all the children in families where baby-walkers were applied and with "baby-walkers/day" indexes being $\geq 1 \mathrm{bw} / \mathrm{d}$ amounted to:

-10.57 months (M without baby-walkers) 10.9 months $(\mathrm{M}$ with baby-walkers, all children $)=$ - 0.33 months (10.04 days);

- months (M without baby-walkers) -11 months $(\mathrm{M}$ in baby-walkers $\geq 1$ bw/d) $=-\mathbf{0 . 4 3}$ months (13.08 days).

We confirmed co-variation of bw/d index (for $\geq 1$ bw/d with authenticity $\mathrm{p}=0.035$ ) and delays in walking on one's own; we also revealed a trend of increasing influence at high values of "babywalkers/day" index.

We detected that more children in "babywalkers" group didn't walk on their own than in "without baby-walkers" one.

This point is confirmed by our analysis of the fourfold table and calculation of risks. We revealed a statistically authentic $(\mathrm{p}<0.05)$ weak correlation and relative risk $(R R)=1.439$. The latter is the evidence there is a delay in motor development.

The 2nd and the 3rd examinations confirmed there was a correlation between baby-walkers and

\footnotetext{
${ }^{6}$ Moving with support is when a baby moves on two feet, on its own, and supports itself with objects or a parent's hand, making more than 5 steps, with a progress.
} 
tiptoe walking. The results are given in Table 6 .

Table 6

Parameters of correlation between baby-walkers and a child walking on tiptoes

\begin{tabular}{|l|c|c|}
\hline \multicolumn{1}{|c|}{ Parameter } & $\begin{array}{c}\text { Examination } \\
\text { No. 2 }\end{array}$ & $\begin{array}{c}\text { Examination } \\
\text { No. } 3^{*}\end{array}$ \\
\hline $\begin{array}{l}\text { Correlation } \\
\text { strength, } p \text {-value }\end{array}$ & $\begin{array}{c}\text { Relatively strong, } \\
p<0,01\end{array}$ & $\begin{array}{c}\text { average, } \\
p<0,01\end{array}$ \\
\hline Risk ratio $(R R)$ & $\begin{array}{c}3,56(2,54-4,99 ; \\
C I 95 \%)\end{array}$ & $\begin{array}{c}2,77(1,18-6,49 ; \\
C I 95 \%)\end{array}$ \\
\hline $\begin{array}{l}\text { Risk discrepancy } \\
(R D)\end{array}$ & 0,45 & 0,18 \\
\hline
\end{tabular}

Note: * The sampling is less representative (wider CI, smaller sampling n-123, anamnestic data are less precise)

In our third examination we revealed a longer period of tiptoe walking in "baby-walkers" group. General mean values amounted to $14.58 \pm$ 3.49 months $(95 \% \mathrm{CI}=11.09-18.07$ months $)$ in "baby-walkers' group; $13.00 \pm 2.1$ months $(95 \%$ CI 10.09-15.1 months) in "without baby-walkers" group. Discrepancies were statistically authentic $(\mathrm{t}=2.61 ; \mathrm{p}<0.05 ; \mathrm{U}=58 \mathrm{p}<0.01)$.

As for the 2nd examination, when we calculated chi-square and Pearson's contingency coefficient for specific intervals of bw/d index, we naturally revealed a greater influence exerted on patterns of walking under longer periods of babywalkers applications.

Nowadays some examinations are being performed in order to get better insights into possible influence exerted by baby-walkers on development on idiopathic tiptoe walking $[10,41]$ and on static deformations occurrence [43].

We revealed a relatively high additional population risk of tiptoe walking and absence of walking on one's own in all the samplings in all three examinations (Table 7).

Table 7

Assessment of population attributable risk, PAR, in the examinations

\begin{tabular}{|l|c|c|c|}
\hline \multicolumn{1}{|c|}{ Indicator } & $\begin{array}{c}\text { Examination No. 1 baby-walkers } \\
\text { group amounted to } 117 \text { children } \\
(43.66 \%)\end{array}$ & $\begin{array}{c}\text { Examination No. 2 } \\
\text { walkers group amounted to } \\
182 \text { children }(50.84 \%)\end{array}$ & $\begin{array}{c}\text { Examination No. 3 } \\
\text { walkers group amounted to 64 } \\
\text { children }(52.03 \%)\end{array}$ \\
\hline Absence of walking & $P A R=4,45$ & $P A R=5,18$ & $P A R=5,3$ \\
\hline $\begin{array}{l}\text { Tiptoe walking } \\
\text { RD 0.425*, } \%\end{array}$ & $P A R=19,647$ & $P A R=22,878$ & $P A R=23,4135$ \\
\hline $\begin{array}{l}\text { Tiptoe walking } \\
\text { RD 0,18*,\% }\end{array}$ & $P A R=7,86$ & $P A R=9,15$ & $P A R=9,36$ \\
\hline
\end{tabular}

Note: ${ }^{*}$ The 2 nd and the 3 rd examination respectively, see Table 6.

When assessing discrepancies in risks, it is advisable to rely on the results obtain in the second examination as the third sampling is less representative, and, consequently, all the data are less precise.

When we compared all the data on the phenomenon obtained in all three examinations described above, we revealed a decrease in application of baby-walkers over from 52.03\% in 2013 to $43.66 \%$ in 2015.

In our opinion, it has happened due to substantial educational work performed over recent years by pediatricians and their efforts aimed at raising awareness among parents and guardians about threats caused by such devices.

Basically, all the obtained results allowed to come to several conclusions:

1. Frequency of baby-walkers application among children in Rzhev and Rzhev district as a representative Russian region is close to average world frequency $62.11 \% \pm 18.5=43.61$ 80.61(CI $=99 \%)$, but still a bit lower: $43.66 \%$; $50.84 \%$ and $52.03 \%$ in all three samplings.

2. Parents in Rzhev gave the same reasons for application of baby-walkers as their foreign counterparts:

- to entertain a baby/to give a baby something to do (57.26\%);

- to teach a baby to walk/to develop a baby $(40.17 \%)$

- family tradition $(2.56 \%)$

3. Damages and traumas caused by babywalkers are relatively rare in Russian families $(15.35 \%, \mathrm{n}-18)$. We didn't register any injuries that required medical aid in our examinations; all the injuries were insignificant;

4. We didn't reveal any statistically authentic influence exerted by baby-walkers on formation of acquired static deformations in infant age. Such negative consequences possibly occur 
at an older age; however, this assumptions requires further investigation.

Naturally there is no statistically authentic discrepancy in ages at which various development stages begin in "without baby-walkers" groups in comparison with average data obtained worldwide in WHO Motor Development Study [Onis M., 2004].

5. There is no statistically authentic discrepancy between "baby-walkers" group and "without baby-walkers" one as regards an age at which such development stages as "standing with support" and "moving with support" begin; therefore, it confirms an assumption that there is no influence exerted by baby-walkers on children development at these stages.

6. A delay in walking on one's one among children who were put into baby-walkers is confirmed; it amounts to 10-13 days depending on frequency and time spent in baby-walkers a day.

7. We revealed a statistically authentic relatively strong correlation between application of baby-walkers and relative risk of tiptoe walking $(\mathrm{RR}=3.6(2.5-5.0$ for $95 \% \mathrm{CI})$ in the most representative sampling. A longer period of tiptoe walking in "baby-walkers" group proves that baby-walkers exert negative influence on walk- ing patterns. Population attributable risk, or $\mathrm{PAR}$, amounted to $\mathrm{PAR}=4.45 \%$ - $\mathrm{PAR}=5.3 \%$ for the absence of walking on one's own; and PAR $=19.647 \%-23.4135 \%$ for tiptoe walking.

8. Application of baby-walkers among children on the examined territories decreased from $52.03 \%$ to $43.66 \%$ and we think it proves that active campaigns and informing parents and guardians about threats cause by baby-walkers are truly effective.

Given all the above stated, we can be sure that baby-walkers are a real influence factor for the population. However, structure and significance of this influence require further investigation; therefore, we hope that our examinations will continue.

As we join the world scientific society dealing with issues related to baby-walkers application, we urge every expert in the field to cover negative outcomes of their application as profoundly as its only possible.

Funding. Our research was not granted any sponsors' support.

A conflict of interests. The authors state there is no conflict of interests.

\section{References}

1. Kauffman I.B., Ridenour M. Influence of an infant walker on onset and quality of walking pattern of locomotion: an electromyographic investigation. Perceptual and motor skills, 1977, vol. 45, no. 3f, pp. 1323-1329. DOI: 10.2466/pms.1977.45.3f.1323

2. Ridenour M.V. Infant walkers: developmental tool or inherent danger. Perceptual and motor skills, 1982, vol. 55, no. 3f, pp. 1201-1202. doi: 10.2466/pms.1982.55.3f.1201

3. Crouchman M. The effects of baby walkers on early locomotor development. Developmental Medicine \& Child Neurology, 1986, vol. 28, no. 6, pp. 757-761. DOI: 10.1111/j.1469-8749. 1986.tb03929.x

4. Thein M.M., Lee J., Tay V., Ling S.L. Infant walker use, injuries, and motor development. Injury Prevention, 1997, vol. 3, no. 1, pp. 63-66. DOI: 10.1136/ip.3.1.63

5. Siegel A.C., Burton R.V. Effects of baby walkers on motor and mental development in human infants. Journal of Developmental \& Behavioral Pediatrics, 1999, vol. 20, no. 5, pp. 355-360. DOI: 10.1097/00004703-199910000-00010

6. Garrett M., McElroyet A.M., Staines A. Locomotor milestones and baby walkers: cross sectional study. BMJ, 2002, vol. 324, no. 7352, pp. 1494. DOI: 10.1136/bmj.324.7352.1494

7. Shiva F., Ghotbi F., Yavari S.F. The use of baby walkers in Iranian infants. Singapore medical journal, 2010, vol. 51, no. 8, pp. 645-649.

8. Engelbert R.H.H., Van Empelen R., Scheurer N.D., Helders P.J.M., Van Nieuwenhuizenl O. Influence of infant-walkers on motor development: mimicking spastic diplegia? European Journal of Pediatric Neurology, 1999, vol. 3, no. 6, pp. 273-275. DOI: 10.1016/s1090-3798 (99) 90982-0 
9. Sharov A.N., Krivova A.V. Vliyanie detskikh khodunkov na razvitie dvigatel'nykh navykov u mladentsev [Effect of Baby Walkers on the Development of Locomotor Skills in Infants]. Vestnik travmatologii i ortopedii imeni N.N. Priorova, 2016, no. 3, pp. 40-46 (in Russian).

10. Krivova A.V., Sharov A.N. Baby walkers and the phenomenon of toe-walking. Pediatric Traumatology, Orthopaedics and Reconstructive Surgery, 2018, vol. 6, no. 1, pp. 23-32. DOI: 10.17816/ptors6123-32

11. Santos S.L. Paricio Talayero J.M., Salom Pérez A., Grieco Burucúa M., Martín Ruano J., Benlloch Muncharaz M.J., Llobat Estellés T., Beseler Soto B. Patterns of use, popular beliefs and proneness to accidents of a baby walker (go-cart). Bases for a health information campaign. Anales espanoles de pediatria, 1996, vol. 44, no. 4, pp. 337-340.

12. Trinkoff A., Parks P.L. Prevention strategies for infant walker-related injuries. Public Health Reports, 1993, vol. 108, no. 6, pp. 784.

13. Laffoy M., Fitzpatrick P., Jordan M., Dowdall D. Attitudes to and use of baby walkers in Dublin. Injury prevention, 1995, vol. 1, no. 2, pp. 109-111. DOI: 10.1136/ip.1.2.109

14. Bar-on M. E., Boyle R. M., Endriss E. K. Parental decisions to use infant walkers. Injury prevention, 1998, vol. 4, no. 4, pp. 299-300. DOI: 10.1136/ip.4.4.299

15. Kendrick D., Marsh P. Babywalkers: prevalence of use and relationship with other safety practices. Injury Prevention, 1998, vol. 4, no. 4, pp. 295-298. DOI: 10.1136/ip.4.4.295

16. DiLillo D., Damashek A., Peterson L. Maternal use of baby walkers with young children: recent trends and possible alternatives. Injury Prevention, 2001, vol. 7, no. 3, pp. 223-227. DOI: 10.1136/ip.7.3.223

17. Tan N.C., Lim L.H., Gu K. Factors influencing caregiver's use of an infant walker.Asia Pacific Family Medicine, 2003, vol. 2, no. 1, pp. 16-22. DOI: 10.1046/j.1444-1683.2003.00045

18. Shiva F., Ghotbi F., Yavari S.F. The use of baby walkers in Iranian infants. Singapore medical journal, 2010, vol. 51, no. 8, pp. 645-649.

19. Dogan D.G., Bilici M., Yilmaz A.E., Catal F., Keles N. Baby walkers: a perspective from Turkey. Acta paediatrica, 2009, vol. 98, no. 10, pp. 1656-1660. DOI: 10.1111/j.1651-2227.2009.01397

20. Grivna M., Barss P., Al-Hanaee A., Al-Dhahab A., Al-Kaabi F., Al-Muhairi S. Baby walker injury awareness among grade-12 girls in a high-prevalence Arab country in the Middle East. Asia-Pacific journal of public health, 2015, vol. 27, no. 2, pp. NP1507-NP1516. DOI: 10.1177/1010539513498766

21. Committee on Injury and Poison Prevention. Injuries Associated With Infant Walkers. Pediatrics, 2001, vol. 108, no. 3, pp. 790-792. DOI: 10.1542/peds.108.3.790

22. Fazen L.E., Felizberto P.I. Baby walker injuries. Pediatrics, 1982, vol. 70, no. 1, pp. 106-109.

23. Wishon P.M., Huang A., Spangler R.S. Hazard Patterns and Injury Prevention with Infant Walkers and Strollers. 1989, 17 p.

24. Shields B.J., Smith G.A. Success in the Prevention of Infant Walker-Related Injuries: An Analysis of National Data, 1990-2001. Pediatrics, 2006, vol. 117, no. 3, pp. e452-e459. DOI: 10.1542/peds.2005-1916

25. Chiaviello C.T., Christoph R.A., Bond G.R. Infant walker-related injuries: a prospective study of severity and incidence. Pediatrics, 1994, vol. 93, no. 6, pp. 974-976.

26. Petridou E., Simou E., Skondras C., G Pistevos., Lagos P., Papoutsakis G. Hazards of baby walkers in a European context. Injury Prevention, 1996, vol. 2, no. 2, pp. 118-120. DOI: 10.1136/ip.2.2.118

27. Smith G.A., Jo Bowman M., Luria J.W., Shields B.J. Babywalker-related injuries continue despite warning labels and public education. Pediatrics, 1997, vol. 100, no. 2. Available at: http: //pediatrics.aappublications.org/content/100/2/e1 (18.04.2018).

28. Rieder M.J., Schwartz C., Newman J. Patterns of Walker Use and Walker Injury. Pediatric Emergency Care, 1987, vol. 3, no. 1, pp. 59. DOI: 10.1097/00006565-198703000-00022

29. Partington M.D., Swanson J.A., Meyer F.B. Head injury and the use of baby walkers: a continuing problem. Annals of emergency medicine, 1991, vol. 20, no. 6, pp. 652-654. DOI: 10.1016/s01960644 (05) 82386-8

30. Coats T.J., Allen M. Baby walker related injuries--a continuing problem. Emergency Medicine Journal, 1991, vol. 8, no. 1, pp. 52-55. DOI: 10.1136/emj.8.1.52 
31. Walker J.M., Fagard R., Narkiewicz K., Redón J., Zanchetti A., Böhm M., Christiaens T., Cifkova R., De Backer G., Dominiczak A., Galderisi M., Grobbee D.E., Jaarsma T., Kirchhof P., Kjeldsen S.E., Laurent S., Manolis A.J., Nilsson P.M., Ruilope L.M., Schmieder R.E., Sirnes P.A., Sleight P., Viigimaa M., Waeber B., Zannad F.; Task Force Members. Hazardous baby walkers: a survey of use. Pediatric Physical Therapy, 1996, vol. 8, no. 1, pp. 25-30. DOI: 10.1097/00001577-199600810-00005

32. Mancini M.C., Magalhães L.C. Clinical Scenario. 2007.

33. Burrows P., Griffiths P. Do baby walkers delay onset of walking in young children? British journal of community nursing, 2002, vol. 7, no. 11, pp. 581-586.

34. Sala D.A., Shulman L.H., Kennedy R.F., Grant A.D., Y Chu M.L. Idiopathic toe-walking: A review. Developmental medicine and child neurology, 1999, vol. 41, no. 12, pp. 846-848. DOI: $10.1017 / \mathrm{s} 0012162299001681$

35. Shulman L.H., Sala D.A., Y Chu M.L., McCaul P.R., Sandler B.J. Developmental implications of idiopathic toe walking. The Journal of pediatrics, 1997, vol. 130, no. 4, pp. 541-546. DOI: 10.1016/s00223476 (97) 70236-1

36. Tidwell M. The child with tip-toe gait. International Pediatrics, 1999, vol. 14, pp. 235-238.

37. Brouwer B., Davidson L.K., Olney S.J. Serial casting in idiopathic toe-walkers and children with spastic cerebral palsy. Journal of Pediatric Orthopaedics, 2000, vol. 20, no. 2, pp. 221-225. DOI: 10.1097/01241398-200003000-00017

38. Fragniere B., Garoflid N., Dutoit M. Mon enfant marche sur la pointe des pieds. Revue médicale de la Suisse romande, 2000, vol. 120, no. 10, pp. 811-814.

39. Stricker S.J. Evaluation and treatment of the child with tiptoe gait. International Pediatrics, 2006, vol. 21 , no. 2 , pp. 91.

40. Sutherland D.H., Olshen R.A., Cooper L. The development of mature gait. J. Bone. Joint. Surg. Am., 1980, vol. 62, no. 3, pp. 336-353. DOI: 10.2106/00004623-198062030-00004

41. Martín-Casas P., Ballestero-Pérez R., Meneses-Monroy A., Beneit-Montesinos J.V., AtínArratibel M.A., Portellano-Pérez J.A. Neurodevelopment in preschool idiopathic toe-walkers. Neurologia (English Edition), 2017, vol. 32, no. 7, pp. 446-454. DOI: 10.1016/j.nrleng.2016.02.006

42. Onis M. WHO Motor Development Study: Windows of achievement for six gross motor development milestones. Acta Paediatrica, 2006, vol. 95, no. S450, pp. 86-95.

43. Shafeek M.M., El-Negmy E.H. Pilot Study: The Onto Ward Effect of Baby Walker Usage on Gait Pattern in Three Years Normal Children. Med. J. Cairo Univ., 2016, vol. 84, no. 2, pp. 379-383.

Sharov A.N., Krivova A.V., Rodionova S.S. Application of baby walkers in Russia: epidemiological aspects. Health Risk Analysis, 2018, no. 3, pp. 63-75. DOI: 10.21668/health.risk/2018.3.07.eng

Received: 29.05 .2018

Accepted: 21.09.2018

Published: 30.09 .2018 